\title{
Self-healing materials enable free-standing seamless large-scale 3D printing
}

\author{
Han Zuo ${ }^{1}$, Zenghe Liu ${ }^{1}$, Luzhi Zhang ${ }^{1}$, Gengxin Liu ${ }^{1,2}$, Xikai Ouyang ${ }^{1,2}$, Qingbao Guan ${ }^{1}$, \\ Qilin $\mathrm{Wu}^{1^{*}}$ and Zhengwei You ${ }^{{ }^{*}}$
}

\begin{abstract}
Three-dimensional (3D) printing has had a large impact on various fields, with fused deposition modeling (FDM) being the most versatile and cost-effective 3D printing technology. However, FDM often requires sacrificial support structures, which significantly complicates the processing and increases the cost. Furthermore, poor layer-to-layer adhesion greatly affects the mechanical stability of 3D-printed objects. Here, we present a new Print-Healing strategy to address the aforementioned challenges. A polymer ink (Cu-DOU-CPU) with synergetic triple dynamic bonds was developed to have excellent printability and room-temperature self-healing ability. Objects with various shapes were printed using a simple compact 3D printer, and readily assembled into large sophisticated architectures via self-healing. Triple dynamic bonds induce strong binding between layers. Additionally, damaged printed objects can spontaneously heal, which significantly elongates their service life. This work paves a simple and powerful way to solve the key bottlenecks in FDM 3D printing, and will have diverse applications.
\end{abstract}

Keywords: dynamic bonds, self-healing, 3D printing, supportfree, interlayer adhesion

\section{INTRODUCTION}

Three-dimensional (3D) printing can readily fabricate complex $3 \mathrm{D}$ structures, which is hard to achieve by traditional processing methods $[1,2]$. Therefore, $3 \mathrm{D}$ printing has wide applications in various fields, such as electronics, biomedical engineering, energy industry, and aerospace [3-14]. There are many types of 3D printing technologies such as digital light processing (DLP), selective laser sintering (SLS), stereolithography (SLA), fused deposition modeling (FDM), and direct ink writing (DIW) $[15,16]$. Among these techniques, FDM is the most popular in several industries due to its low cost, simplicity of operation, and compatibility with a wide range of materials [17-19].

However, FDM of typical polymers faces some challenges. First, auxiliary sacrificial support structures are usually necessary for sophisticated objects, to maintain the desired shape during the printing process. Moreover, post-processing is required to remove the supports [17]. Support structures increase the processing steps, require relatively complex $3 \mathrm{D}$ printers, and lead to high production costs. Furthermore, removing the supports may damage the printed objects [20]. Recently, multi-axis 3D printing systems have been developed to reduce the need for support structures [21-23]. However, adding degrees of freedom to a $3 \mathrm{D}$ printing system makes it challenging to define slicing and avoid collision during printing, and increases the complexity and cost. Second, the layer-bylayer process in all FDM typically causes weak interlayer adhesion in printed objects [24]. Accordingly, cracks and deformations are easily generated during use, which greatly shorten the service life of the fabricated objects. Introducing crosslinks between layers provides an appealing solution to weak interlayer adhesion $[19,25,26]$. Via high energy ionizing irradiation, crosslinking has been induced in 3D-printed polymer objects [26]. However, this approach requires complicated processing, and irradiation dosages must be precisely controlled to prevent degradation of mechanical properties due to chain scission becoming dominant. The thermo-induced DielsAlder reaction has been employed to improve the interlayer adhesion [19]. However, extra cooling system in addition to a $3 \mathrm{D}$ printer is needed to maintain the shape during printing. Furthermore, the dense crosslinking makes these polymers rigid. Third, the customized 3D

\footnotetext{
${ }^{1}$ State Key Laboratory for Modification of Chemical Fibers and Polymer Materials, Shanghai Belt and Road Joint Laboratory of Advanced Fiber and Low-Dimension Materials (Donghua University), College of Material Science and Engineering, Donghua University, Shanghai 201620, China

${ }^{2}$ Center for Advanced Low-Dimension Materials, Donghua University, Shanghai 201620, China

* Corresponding authors (emails: wql@dhu.edu.cn (Wu Q); zyou@dhu.edu.cn (You Z))
} 
printed objects are integrally formed, and thus cannot easily be partially repaired upon damage. Recently, dynamic polymers have been used to solve this problem [27-29]. Nevertheless, the requirement for external stimuli such as heat, light, and solvents greatly impedes their application. Fourthly, the sizes of printed objects are often limited by the size of the 3D printer. It is difficult to obtain large-scale objects using compact printers [30].

To the best of our knowledge, there is no effective method to solve all the above problems simultaneously. We propose a print-healing strategy based on spontaneous self-healing materials with dynamic networks to address these challenges. Here, we demonstrate this strategy via $\mathrm{Cu}$ (II)-dimethylglyoxime-urethane (DOU)complex-based thermoset polyurethane polymers $(\mathrm{Cu}-$ DOU-CPU) with multiple dynamic bonds including reversible $\mathrm{DOU}, \mathrm{Cu}(\mathrm{II})-\mathrm{DOU}$ coordination, and hydrogen bonds. A suitable combination of these enables the material to be FDM 3D-printed at elevated temperatures, quickly solidified at room temperature, and possess excellent self-healing capability (Fig. 1). Inspired by Lego bricks, we took advantage of the room-temperature selfhealing property to assemble 3D-printed blocks into large sophisticated objects without utilizing support structures. Moreover, the triple dynamic bonds significantly improved layer-to-layer adhesion in the printed objects. Furthermore, subsequent mechanical damage can generally be readily repaired via self-healing without any external stimulus.

\section{EXPERIMENTAL SECTION}

\section{Materials}

Polytetramethylene ether glycol (PTMEG, $M_{\mathrm{n}}=$ $\sim 1000 \mathrm{~g} \mathrm{~mol}^{-1}$ ), polypropylene glycol (PPG, $M_{\mathrm{n}}=$ $\sim 2000 \mathrm{~g} \mathrm{~mol}^{-1}$ ), isophorone diisocyanate (IPDI, 99\%) and dibutyltin dilaurate (DBTDL, 95\%) were purchased from Aladdin. Dimethylglyoxime (DMG, 98\%), glycerol (99\%), and copper(II) chloride $\left(\mathrm{CuCl}_{2}, 99 \%\right)$ were purchased from Sinopharm Chemical Reagent Co. Acetone (99.8\%) was purchased from Yonghua Chemical Technology (Jiangsu) Co. All reagents were used as received without further purification unless otherwise noted.

\section{Synthesis of Cu-DOU-CPU polymers}

$\mathrm{Cu}-\mathrm{DOU}-\mathrm{CPU}_{0.3}-\mathrm{T}$ synthesis is discussed below. The other $\mathrm{Cu}-\mathrm{DOU}-\mathrm{CPU}$ polymers were synthesized in a similar procedure (detailed various formulations are shown in Table S1). PTMEG $(6 \mathrm{~g}, 2 \mathrm{mmol})$, DMG $(0.696 \mathrm{~g}$, $2 \mathrm{mmol})$, glycerol $(0.0414 \mathrm{~g}, 0.3 \mathrm{mmol})$ and $\mathrm{CuCl}_{2}$
$(0.0064 \mathrm{~g}, 0.016 \mathrm{mmol})$ were added to $20 \mathrm{~mL}$ of acetone in a glass vessel and stirred with a magnetic stirrer to form a homogeneous solution. IPDI $(2.9637 \mathrm{~g}$, $4.45 \mathrm{mmol})$ and DBTDL $(0.09 \mathrm{~g})$ were added and reacted for $2 \mathrm{~h}$ at $50^{\circ} \mathrm{C}$. Then, the mixture was poured into a Teflon mold and reacted at $50^{\circ} \mathrm{C}$ for $24 \mathrm{~h}$ before further curing in a vacuum oven at $70^{\circ} \mathrm{C}$ for another $24 \mathrm{~h}$ to produce $\mathrm{Cu}-\mathrm{DOU}-\mathrm{CPU}_{0.3}-\mathrm{T}$.

\section{D printing}

Printing was carried out using a GeSiM BioScaffolder BS3.2 printer with a nozzle diameter of $0.4 \mathrm{~mm}$. The 3D models of the samples were designed using Solidwork software. $\mathrm{Cu}-\mathrm{DOU}-\mathrm{CPU}_{0.3}-\mathrm{T}$ polymer was crushed into small pieces and loaded into the print-head, the printhead temperature was set to $100^{\circ} \mathrm{C}$, and held at this temperature for $10 \mathrm{~min}$ to completely de-crosslink the polymer before printing. The extrusion speed and deposition speed were 0.005 and $4.5 \mathrm{~mm} \mathrm{~s}^{-1}$, respectively. All printing paths were controlled by an external personal computer control system. After printing, 3D-printed parts were assembled by hand into the designed architectures. Finally, the assembled architectures and 3D printed objects for tensile tests were moved to an ambient environment at $25^{\circ} \mathrm{C}$ for $72 \mathrm{~h}$ before testing.

\section{General characterizations}

Attenuated total reflectance Fourier transform infrared (ATR-FTIR) spectra were collected using a Nicolet 8700 spectrometer with ATR attachment. In-situ variabletemperature FTIR spectra were collected using the spectrometer with a programmable heating device. Rheological measurement was performed on a Haake Mars III rheometer using 8-mm parallel-plate geometry. Strain sweeps were performed to determine the linear viscoelastic region. Temperature sweeps were performed at a fixed frequency of $10 \mathrm{rad} \mathrm{s}^{-1}$ and a fixed strain of $0.1 \%$ from 25 to $130^{\circ} \mathrm{C}$ at a heating rate of $3^{\circ} \mathrm{C} \mathrm{min}^{-1}$. Isothermal frequency sweeps were conducted to determine the storage moduli $\left(G^{\prime}\right)$ and loss moduli $\left(G^{\prime \prime}\right)$ over a frequency range from 0.1 to $10 \mathrm{~Hz}$ under a fixed strain of $0.1 \%$ at 25 and $100^{\circ} \mathrm{C}$, respectively. The steady-state viscosities under different shear rates were evaluated at $100^{\circ} \mathrm{C}$ between 0.1 and $100 \mathrm{~s}^{-1}$. Thermogravimetric analysis (TGA) was performed on a Discovery TGA. The sample was heated at a constant rate of $20^{\circ} \mathrm{C} \mathrm{min}$ from 40 to $800^{\circ} \mathrm{C}$ under a nitrogen atmosphere. Dynamic mechanical analysis (DMA) was performed on a TAQ800 DMA utilizing rectangular films (ca. $1 \mathrm{~mm}(\mathrm{~T}) \times$ $3 \mathrm{~mm}(\mathrm{~W}) \times 6 \mathrm{~mm}(\mathrm{~L}))$. Samples were tested at a fre- 


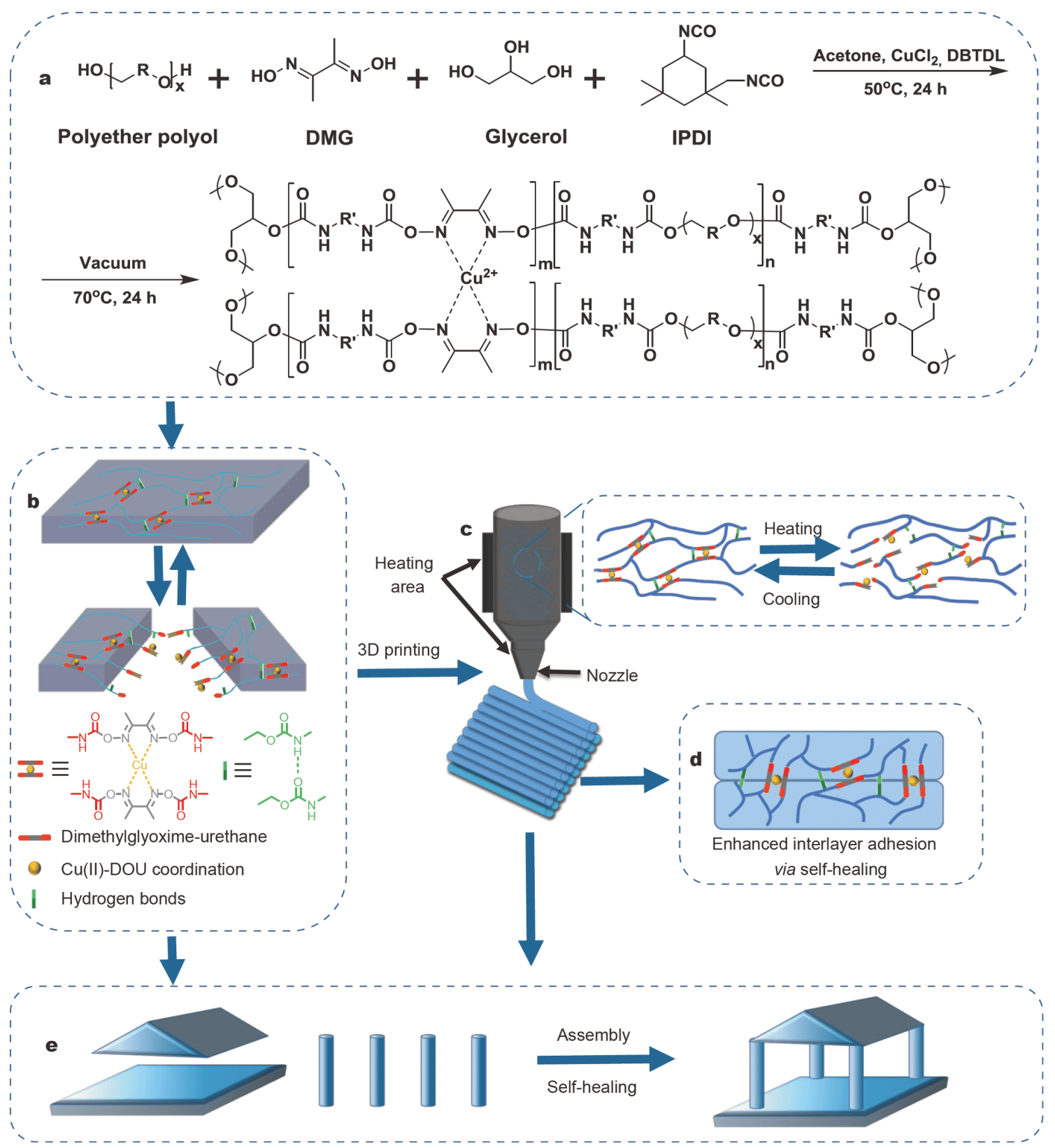

Figure 1 Design of print-healing strategy and corresponding self-healing polymer ink Cu-DOU-CPU. (a) Synthesis of the Cu-DOU-CPU polymers; (b) schematic of self-healing of Cu-DOU-CPU polymers; (c) 3D printing process of Cu-DOU-CPU; (d) enhanced interlayer adhesion of 3D-printed object; (e) schematic showing assembly of 3D-printed parts.

quency of $1 \mathrm{~Hz}$, a strain of $0.1 \%$, and a heating rate of $10^{\circ} \mathrm{C} \mathrm{min}^{-1}$ in air. The glass transition temperature $\left(T_{\mathrm{g}}\right)$ was calculated from the peak of the loss modulus curve. Mechanical properties were investigated using an MTS E42 tensile machine with a $100-\mathrm{N}$ load cell. Rectangular tensile bars (ca. $1 \mathrm{~mm}(\mathrm{~T}) \times 3 \mathrm{~mm}(\mathrm{~W}) \times 20 \mathrm{~mm}(\mathrm{~L}))$ cut from synthetic $\mathrm{Cu}-\mathrm{DOU}-\mathrm{CPU}_{0.3}-\mathrm{T}$ sheets and 3D-printed sheets with different print patterns were used. At least five specimens were tested for each sample. A deflection rate of $100 \mathrm{~mm} \mathrm{~min}^{-1}$ was used for tests at room temperature $\left(25^{\circ} \mathrm{C}\right)$.

\section{Self-healing experiments}

Self-healing tests were investigated by surface scratch recovery and restoration of mechanical properties for different durations. A blade was used to make 15- to 30- 
$\mu$ m-wide scratches on a $\mathrm{Cu}-\mathrm{DOU}_{0.3}$-CPU-T film. The changes of the scratch were monitored by an optical microscope (MDA2000, Future Optics) at room temperature. Restoration of the mechanical properties was performed by bringing the two individual cut specimens back into contact at room temperature for various time periods. The mechanical properties of final healed specimens were obtained after healing for $120 \mathrm{~h}$.

\section{Statistical analysis}

Statistical analysis was performed using independent $t$ test with a minimum confidence level of $<0.05$ for statistical significance. All values are reported as the mean \pm standard deviation (s.d.).

\section{RESULTS AND DISCUSSION}

\section{Synthesis and printability of the Cu-DOU-CPU polymers} For FDM 3D printing, it is important that the ink has good printability. Accordingly, we prepared a series of $\mathrm{Cu}-\mathrm{DOU}-\mathrm{CPU}$ materials with triple dynamic bonds including reversible DOU, $\mathrm{Cu}(\mathrm{II})$-DOU coordination, and hydrogen bonds and investigated their printability. Samples of $\mathrm{Cu}-\mathrm{DOU}-\mathrm{CPU}_{x^{-}} \mathrm{y}$ were synthesized via polycondensation of DMG, polyether polyol, glycerol, IPDI, $\mathrm{CuCl}_{2}$, and catalyst DBTDL ((Fig. 1a and Table S1) [31]. Here, $x$ represents the molar ratio of glycerol, where $x=$ 0.3 or $0.5 ; \mathrm{y}=\mathrm{T}$ represents using PTMEG as the polyether polyol, and $\mathrm{y}=\mathrm{P}$ represents using PPG. 3D-printable polymer must possess suitable viscoelastic properties to allow flow during shearing and extrusion, and retain the 3D structure without collapse after extrusion $[17,32,33]$. Both $\mathrm{Cu}-\mathrm{DOU}-\mathrm{CPU}_{0.3}-\mathrm{P}$ and $\mathrm{Cu}-\mathrm{DOU}-\mathrm{CPU}_{0.5}-\mathrm{P}$ had an amorphous soft sticky state at room temperature and could not retain the desired shape, and thus were not suitable for $3 \mathrm{D}$ printing. $\mathrm{Cu}-\mathrm{DOU}-\mathrm{CPU}_{0.3}-\mathrm{T}$ and $\mathrm{Cu}-$ DOU-CPU $\mathrm{C}_{0.5} \mathrm{~T}$ could be extruded from an injection syringe at $130^{\circ} \mathrm{C}$ and solidified quickly upon cooling (Table S1). ATR-FTIR was used to characterize the structures of $\mathrm{Cu}-\mathrm{DOU}-\mathrm{CPU}_{0.3}-\mathrm{T}$ and $\mathrm{Cu}-\mathrm{DOU}-\mathrm{CPU}_{0.5}-\mathrm{T}$. The peak at around $2271 \mathrm{~cm}^{-1}$ assigned to the $\mathrm{N}=\mathrm{C}=\mathrm{O}$ bond disappeared, whereas the peaks at 3312 and $1718 \mathrm{~cm}^{-1}$ respectively corresponding to $\mathrm{N}-\mathrm{H}$ and $\mathrm{C}=\mathrm{O}$ bonds increased, which revealed the formation of urethane group and complete reaction of the monomer IPDI (Fig. S1).

Next, their suitability for FDM 3D printing was studied in detail by rheological analysis. The energy storage moduli $\left(G^{\prime}\right)$, loss moduli $\left(G^{\prime \prime}\right)$, and complex viscosities of $\mathrm{Cu}-\mathrm{DOU}-\mathrm{CPU}_{0.3}-\mathrm{T}$ and $\mathrm{Cu}-\mathrm{DOU}-\mathrm{CPU}_{0.5}-\mathrm{T}$ obviously decreased with increased temperature (Fig. 2a and b). This result indicates that the disassociation of triple dynamic bonds at elevated temperatures disconnected the molecular network of the polymer, making the flow units smaller and easier to move. $\mathrm{Cu}-\mathrm{DOU}-\mathrm{CPU}_{0.5}-\mathrm{T}$ showed higher $G^{\prime}, G^{\prime \prime}$, and complex viscosity than Cu-DOU$\mathrm{CPU}_{0.3}-\mathrm{T}$, owing to the increased crosslinking degree corresponding to higher glycerol ratio. The increased crosslinking degree made the flow units larger and reduced their mobility. The point of intersection between $G^{\prime}$ and $G^{\prime \prime}$ indicates the transition from solid to liquid state [34]. The transition temperatures of $\mathrm{Cu}-\mathrm{DOU}-\mathrm{CPU}_{0.3^{-}} \mathrm{T}$ and $\mathrm{Cu}-\mathrm{DOU}-\mathrm{CPU}_{0.5}-\mathrm{T}$ were 88 and $124^{\circ} \mathrm{C}$, respectively. To reduce the potential side reactions of dissociated isocyanate group at higher temperatures [35], Cu-DOU$\mathrm{CPU}_{0.3}-\mathrm{T}$ was selected for further study. The results of the frequency sweep rheological experiment revealed that $\mathrm{Cu}-$ DOU-CPU $\mathrm{U}_{0.3}-\mathrm{T}$ possessed an elastic-like behavior at $25^{\circ} \mathrm{C}$ where $G^{\prime}$ was higher than $G^{\prime \prime}$, and a fluid-like behavior at $100^{\circ} \mathrm{C}$ where $G^{\prime \prime}$ was higher than $G^{\prime}$ (Fig. $2 \mathrm{c}$ and d). $\mathrm{Cu}$ DOU-CPU $\mathrm{U}_{0.3}$-T showed a diminishing trend in the viscosity with increasing shear rate at $100^{\circ} \mathrm{C}$, which demonstrated the shear-thinning ability of the polymer (Fig. 2e). Hence, Cu-DOU-CPU ${ }_{0.3}-\mathrm{T}$ polymer could be smoothly squeezed out of the $3 \mathrm{D}$-printer nozzle at $100^{\circ} \mathrm{C}$. Printed filaments showed good shape retention at room temperature after extrusion, which is necessary for layer-bylayer deposition (Fig. S2). TGA confirmed good thermal stability of $\mathrm{Cu}-\mathrm{DOU}-\mathrm{CPU}_{0.3}-\mathrm{T}$ with a $5 \%$ weight loss at $221^{\circ} \mathrm{C}$, which indicated that stable printing at moderate temperature would be possible (Fig. S3).

The complex viscosity of $\mathrm{Cu}-\mathrm{DOU}-\mathrm{CPU}_{0.3}-\mathrm{T}$ decreased under the heating process, which was attributed to the disassociation of triple dynamic bonds. Hydrogen bonds and metal coordination bonds have been proved to be thermo-reversible $[30,36]$. The thermal reversibility of the DOU bonds was characterized by in situ variable-temperature FTIR spectroscopy (Fig. 2f). There was almost no characteristic peak at $2271 \mathrm{~cm}^{-1}$ corresponding to $\mathrm{N}=\mathrm{C}=\mathrm{O}$ bonds below $90^{\circ} \mathrm{C}$. Whereas the peak appeared and increased as the temperature rose above $100^{\circ} \mathrm{C}$, which implicated the dissociation of DOU bonds. The dissociation of hydrogen bonds, DOU bonds, and $\mathrm{Cu}(\mathrm{II})-$ DOU coordination bonds at elevated temperatures disconnected the molecular network of $\mathrm{Cu}-\mathrm{DOU}-\mathrm{CPU}_{0.3^{-}} \mathrm{T}$ and enabled printing (Fig. 1c). In addition, DMA was performed to investigate the thermal properties of $\mathrm{Cu}$ DOU-CPU ${ }_{0.3}-\mathrm{T}$. The $T_{\mathrm{g}}$ of $\mathrm{Cu}-\mathrm{DOU}-\mathrm{CPU}_{0.3}-\mathrm{T}$ was $-33.1^{\circ} \mathrm{C}$ (Fig. S4), which indicated the flexibility of $\mathrm{Cu}-$ DOU-CPU ${ }_{0.3}-\mathrm{T}$ at room temperature. 

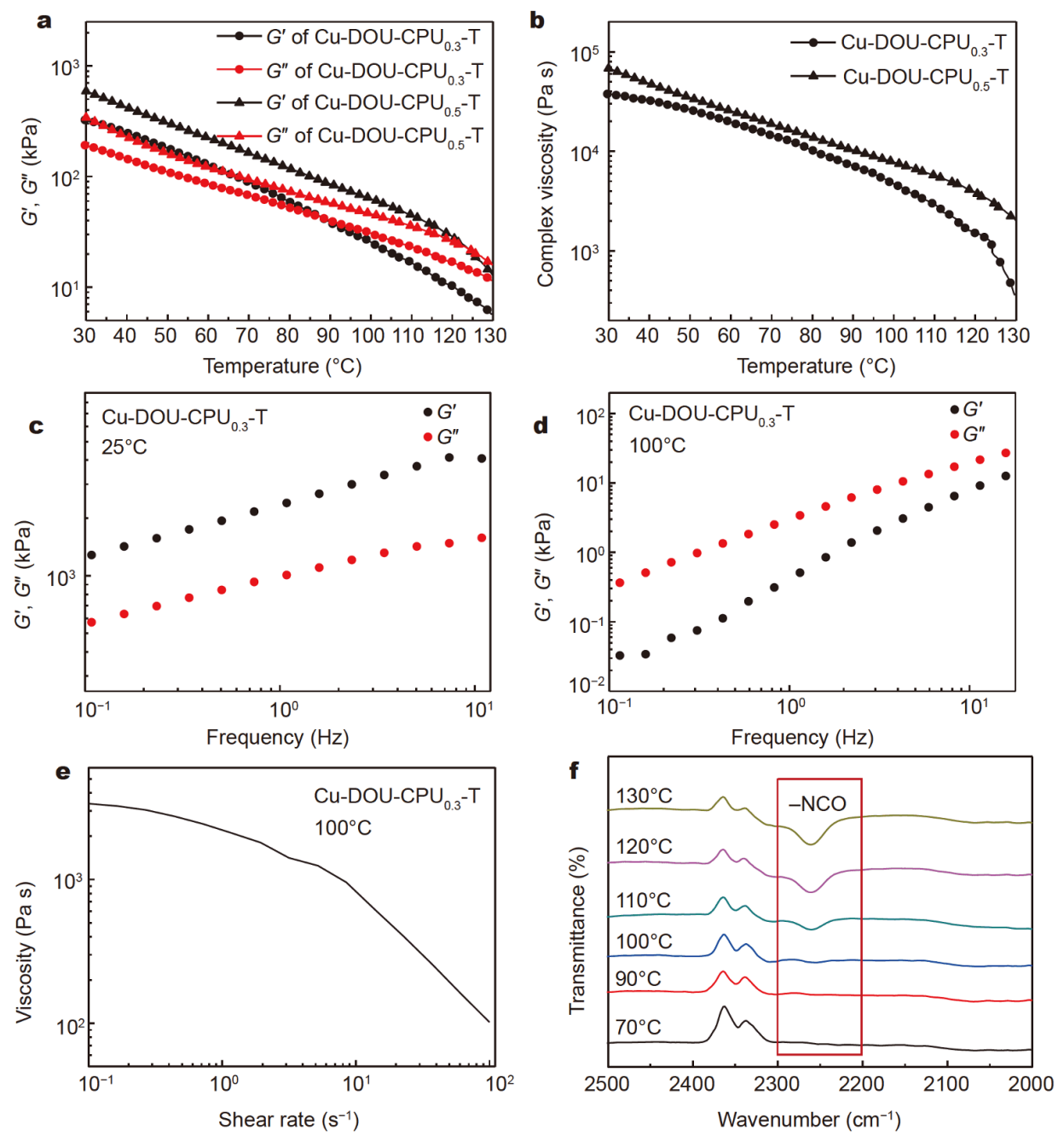

Figure 2 Dynamic properties and printability of $\mathrm{Cu}$-DOU-CPU polymers. (a) Temperature-dependent curves of storage modulus $\left(G^{\prime}\right)$ and loss modulus $\left(G^{\prime \prime}\right)$ for Cu-DOU-CPU $\mathrm{C}_{0.3}-\mathrm{T}$ and $\mathrm{Cu}-\mathrm{DOU}-\mathrm{CPU}_{0.5}-\mathrm{T}$; (b) corresponding complex viscosity curves of Cu-DOU-CPU $0.3^{-} \mathrm{T}$ and $\mathrm{Cu}-\mathrm{DOU}-$ $\mathrm{CPU}_{0.5}-\mathrm{T}$; (c, d) frequency-dependent curves of storage modulus $\left(G^{\prime}\right)$ and loss modulus $\left(G^{\prime \prime}\right)$ for $\mathrm{Cu}-\mathrm{DOU}-\mathrm{CPU}_{0.3}-\mathrm{T}$ at $(\mathrm{c}) 25^{\circ} \mathrm{C}$ and $(\mathrm{d}) 100^{\circ} \mathrm{C}$; (e) curve of the viscosity of $\mathrm{Cu}-\mathrm{DOU}-\mathrm{CPU}_{0.3^{-}} \mathrm{T}$ as a function of shear rate at $100^{\circ} \mathrm{C}$; (f) in situ variable-temperature $\mathrm{FTIR}$ spectra of Cu-DOU-CPU $\mathrm{Cu}_{0.3^{-}}$ T.

Self-healing properties of the $\mathrm{Cu}-\mathrm{DOU}-\mathrm{CPU}_{0.3}-\mathrm{T}$ polymer The room-temperature self-healing properties of the $\mathrm{Cu}$ DOU-CPU $\mathrm{C}_{0.3} \mathrm{~T}$ polymer were evaluated in detail. An optical microscope was used for monitoring the surface scratch recovery of $\mathrm{Cu}-\mathrm{DOU}-\mathrm{CPU}_{0.3}-\mathrm{T}$. A blade was used to make 15 - to $30-\mu \mathrm{m}$-wide scratches on a $\mathrm{Cu}-\mathrm{DOU}$ $\mathrm{CPU}_{0.3}$ - $\mathrm{T}$ film. The crack disappeared almost completely after healing at room temperature for $75 \mathrm{~min}$ (Fig. 3a). The instant bulky self-healing ability of $\mathrm{Cu}-\mathrm{DOU}-\mathrm{CPU}_{0.3^{-}}$ $\mathrm{T}$ was assessed. The specimen was cut into two pieces, which were brought back into contact under ambient conditions without external force. After 3 min, the healed specimen could be stretched to $150 \%$ without fracture (Fig. 3b). Uniaxial tensile testing was further applied to quantitatively evaluate the final self-healing properties of $\mathrm{Cu}-\mathrm{DOU}-\mathrm{CPU}_{0.3}-\mathrm{T}$ (Fig. $3 \mathrm{c}$ and d). The relative recovery rate (\%) was defined as the ratio of the toughness of the original and healed samples. The Young's modulus, tensile strength, maximum elongation and toughness of the original samples were $(4.79 \pm 0.09),(7.43 \pm 0.92) \mathrm{MPa}$, $(677.41 \pm 22.61) \%$, and $(20.99 \pm 1.60) \mathrm{MJ} \mathrm{m}^{-3}$, respectively. The Young's modulus, maximum elongation and toughness of healed samples restored to $(4.77 \pm 0.08) \mathrm{MPa}, \quad(668.56 \pm 44.11) \%, \quad$ and $(19.68 \pm 1.20) \mathrm{MJ} \mathrm{m}^{-3}$, respectively, without statistical difference to the original samples (Fig. 3d and Figs S5S7). The healed tensile strength was $(5.97 \pm 0.32) \mathrm{MPa}$, slightly lower than the original one. The relative recovery 
a
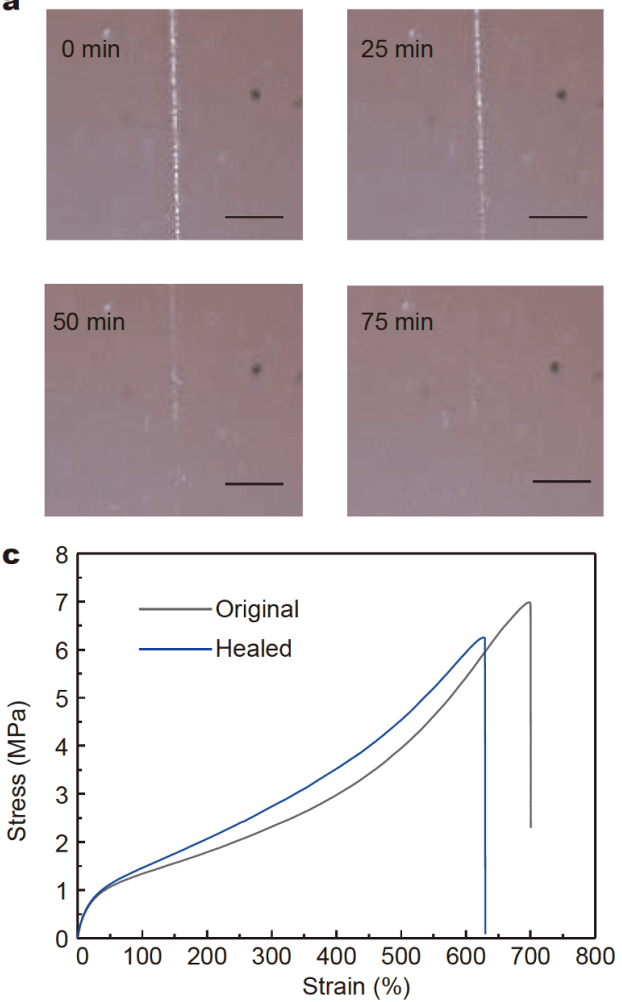
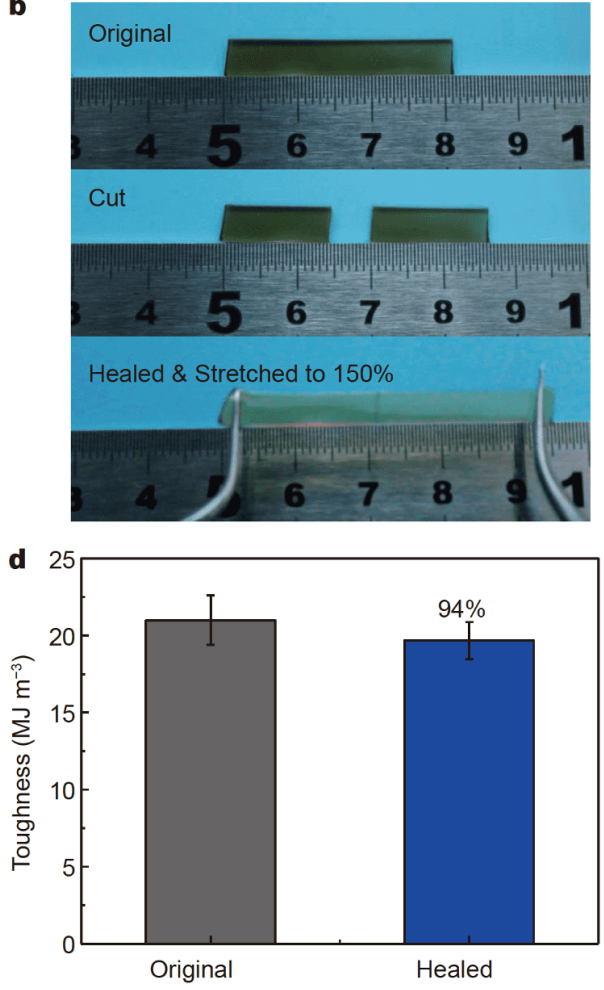

Figure 3 Self-healing properties of the Cu-DOU-CPU ${ }_{0.3}-\mathrm{T}$ polymer (room temperature). (a) Optical microscopy photographs of the healing of the scratch on the Cu-DOU-CPU ${ }_{0.3}-\mathrm{T}$ film. Scale bar: $150 \mu \mathrm{m}$. (b) Photographs of the original, cut, and healed Cu-DOU-CPU ${ }_{0.3}-\mathrm{T}$ specimens under ambient conditions. The healed specimen was stretched to $150 \%$. (c, d) Mechanical recovery of the healed Cu-DOU-CPU $\mathrm{C}_{0.3}-\mathrm{T}$ strips including the tensile stress-strain curves (c) and toughness (d).

rate reached $94 \%$. These results confirmed the spontaneous self-healing capability of Cu-DOU-CPU $\mathrm{C}_{0.3}-\mathrm{T}$ without any external stimulus.

\section{Free assembly of 3D-printed objects via self-healing}

While printing complex architectures such as overhangs using FDM, temporary support structures are indispensable. The introduction of the additional support results in waste of sacrificial support material and increase of printing complexity and duration. The support removal process may even damage the printed structures [20]. Moreover, being limited by the size of the 3D printer, it is difficult to print large objects.

Inspired by Lego bricks, we split a complex geometric digital model into simple parts that could be easily fabricated by $3 \mathrm{D}$ printing, without support structures. Then, the complete complex architectures would be assembled from these parts (Fig. 1e). We fabricated three different structures to demonstrate this design principle, including the Eiffel Tower, a Chinese building, and a ship anchor. First, $\mathrm{Cu}-\mathrm{DOU}-\mathrm{CPU}_{0.3}-\mathrm{T}$ was $3 \mathrm{D}$-printed into small simple parts, which were assembled by hand into large complex objects, and then seamlessly fused together via the room-temperature self-healing. Accordingly, the sophisticated architectures were efficiently produced without additional support structures (Fig. $4 \mathrm{a}$ and b, and Fig. S8), and the self-healed joints of the ship anchor could sustain a weight of $50 \mathrm{~g}$, which proved the strong bonding between the assembled components (Fig. 4c). This strategy of dividing the whole into parts and then assembling the parts into a whole via spontaneous selfhealing is a powerful means to fabricate large sophisticated support-free 3D-printed objects that are not limited in size by the dimensions of the $3 \mathrm{D}$ printer.

\section{Mechanical isotropy of 3D-printed objects}

The mechanical properties of the $3 \mathrm{D}$-printed objects at different printed orientations were compared to evaluate the anisotropy of the objects. We prepared three print patterns, $\mathrm{X}, \mathrm{Y}$, and $\mathrm{Z}$, where the print variation $\mathrm{X}$ consisted of $45^{\circ}$ alternating infill layer pattern, and the print variations $\mathrm{Y}$ and $\mathrm{Z}$ consisted of linear layer patterns 

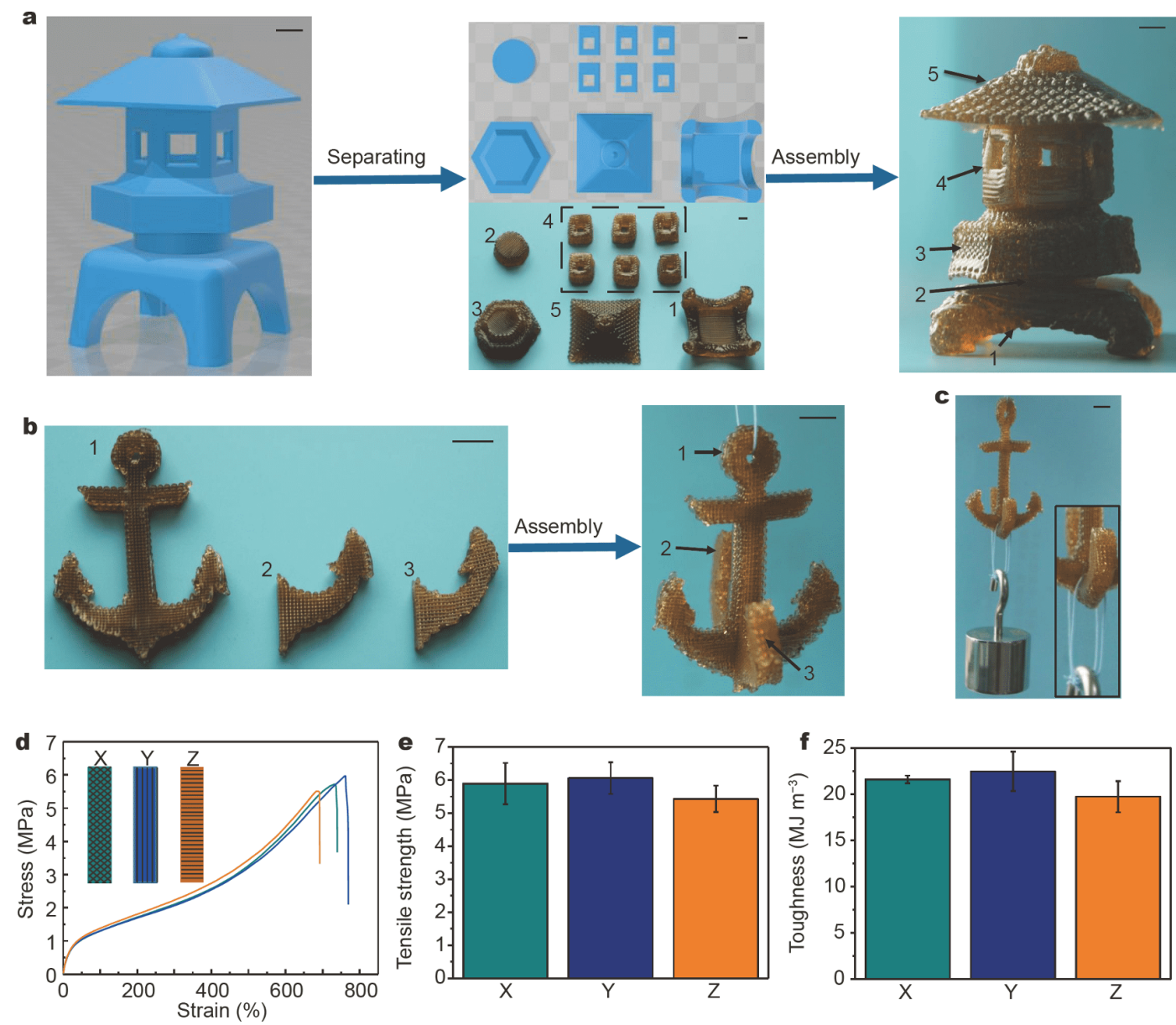

Figure 4 Free assembly of 3D-printed parts into sophisticated objects and mechanical isotropy properties of the 3D-printed objects. (a) Digital model (left and upper middle) and photographs (lower middle and right) of 3D-printed small simple parts, and assembled large complex Chinese building model (scale bar, $5 \mathrm{~mm}$ ). (b) Photographs of the 3D-printed parts and assembled ship anchor (scale bar: $10 \mathrm{~mm}$ ). The numbers in the photographs represent the assembly sequence. $(\mathrm{d}-\mathrm{f})$ Mechanical properties of $\mathrm{X}, \mathrm{Y}$, and $\mathrm{Z}$ pattern samples printed with $\mathrm{Cu}-\mathrm{DOU}-\mathrm{CPU} \mathrm{U}_{0.3}-\mathrm{T}$, including the tensile stress-strain curves (d), tensile strength (e), and toughness (f).

parallel to the $y$-axis and $z$-axis of the machine coordinate system, respectively (Fig. 4d). Isotropy was calculated according to the ratios of ultimate strength and toughness along the $\mathrm{X}$ and $\mathrm{Z}$ patterns compared with that of the $\mathrm{Y}$ pattern. Tensile stress-strain curves of the objects with different print directions were similar, which demonstrated reduced anisotropy of the mechanical properties for different print directions (Fig. 4d). The tensile strengths of the $\mathrm{X}, \mathrm{Y}$, and $\mathrm{Z}$ print patterns were $(5.89 \pm 0.62),(6.06 \pm 0.48)$, and $(5.43 \pm 0.40) \mathrm{MPa}$, respectively (Fig. 4e). The $\mathrm{X}$ and $\mathrm{Z}$ printing patterns exhibited $97.19 \%$ and $89.60 \%$ isotropic behavior relative to the $\mathrm{Y}$ printing pattern. Toughness values for the $\mathrm{X}, \mathrm{Y}$, and $Z$ patterns were $(21.60 \pm 0.40),(22.47 \pm 2.14)$, and $(19.74 \pm$ 1.69) $\mathrm{MJ} \mathrm{m}^{-3}$, respectively (Fig. $\left.4 \mathrm{f}\right)$. The $\mathrm{X}$ and $\mathrm{Z}$ patterns showed $96.13 \%$ and $87.85 \%$ isotropic behavior relative to the Y pattern, respectively. The isotropic behaviors were comparable to those $(80 \%-96 \%)$ of previously reported 3D printed objects strengthened via high-temperature Diels-Alder reactions $[19,37,38]$. Here, the printed objects without any post-treatment showed excellent isotropic properties that confirmed the feasibility of increasing the layer-to-layer adhesion via spontaneous recombination of dynamic hydrogen bonds, $\mathrm{Cu}(\mathrm{II})-\mathrm{DOU}$ coordination bonds, and covalent DOU bonds (Fig. 1d). This provides a facile and efficient way to improve the mechanical properties of resultant $3 \mathrm{D}$ printing objects.

\section{Repair of damage to 3D printed objects via self-healing}

Owing to the integral forming process, customized 3D 
printing objects cannot be easily repaired by replacing broken parts. Thus, the entire 3D objects have to be discarded after damage, causing abundant waste [30]. The room-temperature self-healing property of $\mathrm{Cu}-\mathrm{DOU}$ $\mathrm{CPU}_{0.3}$ - T could effectively solve this problem. As an example, a 3D-printed mesh was locally cut by a scissor. The two broken cross sections were brought back into contact under ambient conditions without external treatment. The fracture could heal spontaneously, and the healed object could resist stretching by tweezers without breaking (Fig. S9). Accordingly, the room-temperature self-healing property could significantly enhance the longevity of 3D-printed objects and reduce resource dissipation.

\section{Wide applicability of print-healing strategy}

It is worth noting that all raw reagents used for synthesizing the $\mathrm{Cu}-\mathrm{DOU}-\mathrm{CPU}_{0.3}$ - $\mathrm{T}$ polymer are common inexpensive industrial chemicals, and the one-step polycondensation process is simple and can be readily scaled up. Thus, $\mathrm{Cu}-\mathrm{DOU}-\mathrm{CPU}_{0.3}-\mathrm{T}$ could be readily produced at a large scale for a wide range of applications. Furthermore, various self-healing materials including silicone, polyamide, polyetherimides, diolefine rubber, and polyurethane materials have been recently developed [3949]. Applying the print-healing strategy to these materials would facilitate the 3D printing of diverse objects with various properties for a wide range of applications.

\section{CONCLUSIONS}

In summary, we have established a new Print-Healing strategy based on an emerging spontaneously self-healing polymer ink to address a series of key challenges of FDM 3D printing. These include avoiding support structures, inducing strong interlayer adhesion, enabling large-size fabrication, and self-healing of subsequent damage. The key to realizing this strategy is the newly designed polymer ink with a suitable combination of a mobile molecular chain, dynamic bonds, and stable networks. This strategy significantly enhances the achievable complexity, size, and performance of FDM 3D printed objects. The entire fabrication process can be performed using common FDM 3D printers without additional treatment. The $3 \mathrm{D}$ printing ink developed here can readily be synthesized from inexpensive commercially available chemicals in one step, which could easily be made available in large quantities. Many self-healing materials can be used with this strategy to produce objects with diverse properties. Overall, this study provides a simple, practical, powerful way based on emerging dynamic chemistry to tailor $3 \mathrm{D}$ objects with sophisticated architectures and outstanding performance, will widen the capability of 3D printing technology, and enable new applications in various fields.

\section{Received 10 December 2020; accepted 31 December 2020;} published online 17 March 2021

1 MacDonald E, Wicker R. Multiprocess 3D printing for increasing component functionality. Science, 2016, 353: aaf2093

2 Zhang D, Jonhson W, Herng TS, et al. A 3D-printing method of fabrication for metals, ceramics, and multi-materials using a universal self-curable technique for robocasting. Mater Horiz, 2020, 7: $1083-1090$

3 Zhu Z, Park HS, McAlpine MC. 3D printed deformable sensors. Sci Adv, 2020, 6: eaba5575

4 Wu T, Gray E, Chen B. A self-healing, adaptive and conductive polymer composite ink for $3 \mathrm{D}$ printing of gas sensors. J Mater Chem C, 2018, 6: 6200-6207

5 Gao F, Xu Z, Liang Q, et al. Osteochondral regeneration with 3Dprinted biodegradable high-strength supramolecular polymer reinforced-gelatin hydrogel scaffolds. Adv Sci, 2019, 6: 1900867

6 Chen Q, Xu R, He Z, et al. Printing 3D gel polymer electrolyte in lithium-ion microbattery using stereolithography. J Electrochem Soc, 2017, 164: A1852-A1857

7 Conner BP, Manogharan GP, Martof AN, et al. Making sense of 3-D printing: Creating a map of additive manufacturing products and services. Addit Manuf, 2014, 1-4: 64-76

$8 \mathrm{Gu}$ Q, Zhu H, Li J, et al. Three-dimensional bioprinting speeds up smart regenerative medicine. Natl Sci Rev, 2016, 3: 331-344

9 Yang Y, Li X, Chu M, et al. Electrically assisted 3D printing of nacre-inspired structures with self-sensing capability. Sci Adv, 2019, 5: eaau9490

10 Chen Y, Zhuang X, Goldfine EA, et al. Printable organic-inorganic nanoscale multilayer gate dielectrics for thin-film transistors enabled by a polymeric organic interlayer. Adv Funct Mater, 2020, 30: 2005069

11 Zhang T, Zhou W, Jia Z, et al. Polydopamine-assisted functionalization of heparin and vancomycin onto microarc-oxidized 3D printed porous Ti6Al4V for improved hemocompatibility, osteogenic and anti-infection potencies. Sci China Mater, 2018, 61: 579592

12 Liu J, Ye J, Pan F, et al. Solid-state yet flexible supercapacitors made by inkjet-printing hybrid ink of carbon quantum dots/graphene oxide platelets on paper. Sci China Mater, 2018, 62: 545-554

13 Alizadeh-Osgouei M, Li Y, Vahid A, et al. High strength porous PLA gyroid scaffolds manufactured via fused deposition modeling for tissue-engineering applications. Smart Mater Med, 2021, 2: 1525

14 Senthil Kumar K, Chen PY, Ren H. A review of printable flexible and stretchable tactile sensors. Research, 2019, 2019: 1-32

$15 \mathrm{Xu} \mathrm{Y,} \mathrm{Wu} \mathrm{X,} \mathrm{Guo} \mathrm{X,} \mathrm{et} \mathrm{al.} \mathrm{The} \mathrm{boom} \mathrm{in} \mathrm{3D-printed} \mathrm{sensor} \mathrm{tech-}$ nology. Sensors, 2017, 17: 1166

16 Wu L, Dong Z, Du H, et al. Bioinspired ultra-low adhesive energy interface for continuous 3D printing: Reducing curing induced adhesion. Research, 2018, 2018: 1-10

17 Truby RL, Lewis JA. Printing soft matter in three dimensions. Nature, 2016, 540: 371-378

18 Nadgorny M, Ameli A. Functional polymers and nanocomposites for 3D printing of smart structures and devices. ACS Appl Mater 
Interfaces, 2018, 10: 17489-17507

19 Yang K, Grant JC, Lamey P, et al. Diels-Alder reversible thermoset 3D printing: Isotropic thermoset polymers via fused filament fabrication. Adv Funct Mater, 2017, 27: 1700318

20 Lim J, Kim YK, Won DJ, et al. 3D printing of freestanding overhanging structures utilizing an in situ light guide. Adv Mater Technol, 2019, 4: 1900118

21 Gao Y, Wu L, Yan DM, et al. Near support-free multi-directional 3D printing via global-optimal decomposition. Graphical Model, 2019, 104: 101034

22 Asif M, Lee JH, Lin-Yip MJ, et al. A new photopolymer extrusion 5-axis 3D printer. Addit Manuf, 2018, 23: 355-361

23 Dai C, Wang CCL, Wu C, et al. Support-free volume printing by multi-axis motion. ACM Trans Graph, 2018, 37: 1-14

24 Kelly BE, Bhattacharya I, Heidari $\mathrm{H}$, et al. Volumetric additive manufacturing via tomographic reconstruction. Science, 2019, 363: 1075-1079

25 Yang H, Li C, Yang M, et al. Printing hydrogels and elastomers in arbitrary sequence with strong adhesion. Adv Funct Mater, 2019, 29: 1901721

26 Shaffer S, Yang K, Vargas J, et al. On reducing anisotropy in 3D printed polymers via ionizing radiation. Polymer, 2014, 55: 59695979

27 Kuang X, Chen K, Dunn CK, et al. 3D printing of highly stretchable, shape-memory, and self-healing elastomer toward novel 4D printing. ACS Appl Mater Interfaces, 2018, 10: 73817388

28 Zhang B, Kowsari K, Serjouei A, et al. Reprocessable thermosets for sustainable three-dimensional printing. Nat Commun, 2018, 9: 1831

29 Wu Q, Zou S, Gosselin FP, et al. 3D printing of a self-healing nanocomposite for stretchable sensors. J Mater Chem C, 2018, 6: 12180-12186

30 Lai JC, Li L, Wang DP, et al. A rigid and healable polymer crosslinked by weak but abundant $\mathrm{Zn}$ (II)-carboxylate interactions. Nat Commun, 2018, 9: 2725

31 Zhang L, Liu Z, Wu X, et al. A highly efficient self-healing elastomer with unprecedented mechanical properties. Adv Mater, 2019, 31: 1901402

32 Rutz AL, Hyland KE, Jakus AE, et al. A multimaterial bioink method for 3D printing tunable, cell-compatible hydrogels. Adv Mater, 2015, 27: 1607-1614

33 Lei D, Yang Y, Liu Z, et al. A general strategy of 3D printing thermosets for diverse applications. Mater Horiz, 2019, 6: 394-404

$34 \mathrm{Wu} \mathrm{Q}$, Wei J, Xu B, et al. A robust, highly stretchable supramolecular polymer conductive hydrogel with self-healability and thermo-processability. Sci Rep, 2017, 7: 41566

35 He Y, Zhang X, Zhang X, et al. Structural investigations of toluene diisocyanate (TDI) and trimethylolpropane (TMP)-based polyurethane prepolymer. J Industrial Eng Chem, 2012, 18: 1620-1627

36 Cordier P, Tournilhac F, Soulié-Ziakovic C, et al. Self-healing and thermoreversible rubber from supramolecular assembly. Nature, 2008, 451: 977-980

37 Appuhamillage GA, Reagan JC, Khorsandi S, et al. 3D printed remendable polylactic acid blends with uniform mechanical strength enabled by a dynamic Diels-Alder reaction. Polym Chem, 2017, 8: 2087-2092

38 Davidson JR, Appuhamillage GA, Thompson CM, et al. Design paradigm utilizing reversible Diels-Alder reactions to enhance the mechanical properties of 3D printed materials. ACS Appl Mater
Interfaces, 2016, 8: 16961-16966

39 Susa A, Bose RK, Grande AM, et al. Effect of the dianhydride/ branched diamine ratio on the architecture and room temperature healing behavior of polyetherimides. ACS Appl Mater Interfaces, 2016, 8: 34068-34079

40 Li CH, Wang C, Keplinger C, et al. A highly stretchable autonomous self-healing elastomer. Nat Chem, 2016, 8: 618-624

41 Chen Y, Kushner AM, Williams GA, et al. Multiphase design of autonomic self-healing thermoplastic elastomers. Nat Chem, 2012, 4: $467-472$

42 Rao YL, Chortos A, Pfattner R, et al. Stretchable self-healing polymeric dielectrics cross-linked through metal-ligand coordination. J Am Chem Soc, 2016, 138: 6020-6027

43 Lai JC, Jia XY, Wang DP, et al. Thermodynamically stable whilst kinetically labile coordination bonds lead to strong and tough selfhealing polymers. Nat Commun, 2019, 10: 1164

44 Wu J, Cai LH, Weitz DA. Tough self-healing elastomers by molecular enforced integration of covalent and reversible networks. Adv Mater, 2017, 29: 1702616

45 Liu Z, Zhang L, Guan Q, et al. Biomimetic materials with multiple protective functionalities. Adv Funct Mater, 2019, 29: 1901058

46 Bapat AP, Sumerlin BS, Sutti A. Bulk network polymers with dynamic B-O bonds: Healable and reprocessable materials. Mater Horiz, 2020, 7: 694-714

47 Guo Q, Huang B, Lu C, et al. A cephalopod-inspired mechanoluminescence material with skin-like self-healing and sensing properties. Mater Horiz, 2019, 6: 996-1004

48 Deng XY, Xie H, Du L, et al. Polyurethane networks based on disulfide bonds: From tunable multi-shape memory effects to simultaneous self-healing. Sci China Mater, 2018, 62: 437-447

49 An XP, Chen JH, Li YD, et al. Rational design of sustainable polyurethanes from castor oil: Towards simultaneous reinforcement and toughening. Sci China Mater, 2018, 61: 993-1000

Acknowledgements This work was supported by the National Natural Science Foundation of China (21991123, 52073049 and 51703148), the Natural Science Foundation of Shanghai (20ZR1402500 and 18ZR1401900), the Belt \& Road Young Scientist Exchanges Project of Science and Technology Commission Foundation of Shanghai (20520741000), Shanghai Belt and Road Joint Laboratory of Advanced Fiber and Low-dimension Materials (Donghua University (DHU), 18520750400), and the Fundamental Research Funds for the Central Universities, DHU Distinguished Young Professor Program (LZA2019001), and the Open Research Fund of Shanghai Center for High-performance Fibers and Composites and the Center for Civil Aviation Composites of Donghua University.

Author contributions Zuo H, Wu Q and You Z conceived the idea and designed the experiments. You $\mathrm{Z}$ directed the entire project. Zuo $\mathrm{H}$ performed the experiments (with involvement of Liu Z, Zhang L, Liu G and Ouyang X). Zuo H, Liu Z, Zhang L, Guan Q and Wu Q contributed to data analysis and interpretation. Zuo $\mathrm{H}$ and You $\mathrm{Z}$ wrote the manuscript. All authors commented on the manuscript.

Conflict of interest The authors declare that they have no conflict of interest.

Supplementary information online version of the paper.
Supporting data are available in the 


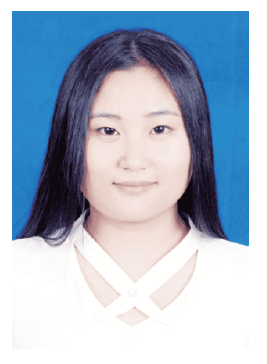

Han Zuo is a PhD student at the State Key Laboratory for Modification of Chemical Fibers and Polymer Materials at Donghua University. From 2016 to now, she has been conducting her master and doctoral research at Donghua University. Her current research involves biomaterials, 3D printing and self-healing polymers.

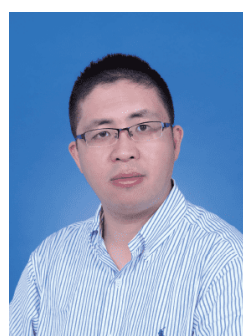

Zhengwei You is a professor and the chair of the Department of Composite Materials at Donghua University. He serves as the director of Research Base of Textile Materials for Flexible Electronics and Biomedical Applications, China Textile Engineering Society. He received his $\mathrm{PhD}$ degree from Shanghai Institute of Organic Chemistry and conducted research at Georgia Institute of Technology, University of Pittsburgh, and Bayer MaterialScience. His current research involves elastomers, biomaterials, 3D printing, and stretchable electronics.

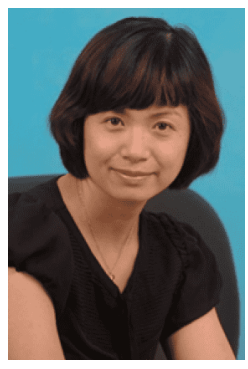

Qilin Wu received her $\mathrm{PhD}$ degree from Donghua University in 2002. As a visiting scholar, she worked at the University of California, Davis for one year from 2006 to 2007. Now she is a full professor of Donghua University. Her research focuses on composite materials.

\section{自愈合材料实现自支撑各向同性3D打印}

左涵 ${ }^{1}$, 刘增贺 ${ }^{1}$, 张珞之 ${ }^{1}$, 刘庚金金 ${ }^{1,2}$, 欧阳希凯 ${ }^{1,2}$, 管清宝 ${ }^{1}$, 吴琪琳 ${ }^{1 *}$, 游正伟 ${ }^{*}$

摘要 $3 \mathrm{D}$ 打印已经在诸多领域产生了重要影响, 其中熔融沉积成 型(fused deposition modeling, FDM) 是最通用和最经济的3D打印 技术. 然而, FDM通常需要支撑结构, 这大大增加了加工的复杂性 和成本. 此外, 层间结合力差极大地影响了FDM 3D打印制品的机 械稳定性. 本文提出了一种新的打印-愈合策略来解决上述挑战. 采 用了三重动态键设计, 研制了一种具有良好的打印性能和室温自 愈能力的聚合物. 利用简便紧凑型的3D打印机打印出了各种形状 的物体, 并通过自修复便捷地将它们组装成大型复杂的三维结构. 三重动态键显著提升了打印制品层与层之间的结合力. 此外, 损坏 的打印品可以自我修复, 这大大延长了它们的使用寿命. 这项工作 为解决FDM $3 \mathrm{D}$ 打印的关键瓶颈问题提供了一种简单有效的方法, 有望在多个领域获得应用. 